\title{
Sexual Harassment Victimization During Emerging Adulthood
}

\section{A Test of Routine Activities Theory and a General Theory of Crime}

\author{
Tammatha A. Clodfelter \\ Michael G. Turner \\ Jennifer L. Hartman \\ Joseph B. Kuhns \\ University of North Carolina-Charlotte
}

\begin{abstract}
Sexual harassment of college students may lead to more serious forms of sexual assault. Few studies have investigated sexual harassment predictors framed within competing theoretical perspectives. In this study, the literature is extended by examining (a) three types of sexual harassment on a college campus, (b) the nature of reporting, and (c) whether routine activities and self-control theories effectively explain sexual harassment. Findings indicate that one fourth of the participants in the sample were sexually harassed, assaulted students are extremely unlikely to officially report incidents, and measures of routine activities theory are important predictors of sexual harassment. Prevention and education policies should focus on increased reporting to university authorities and helping students understand the situational contexts in which these behaviors are likely to occur.
\end{abstract}

Keywords: sexual harassment; routine activities theory; self-control theory; emerging adulthood

$\mathrm{T}$ he developmental period known as "emerging adulthood" has recently attracted the interest of scholars (Arnett, 2000, 2004). Defined as the

Authors' Note: Please address correspondence to Tammatha A. Clodfelter, 2054B Colvard, Department of Criminal Justice, University of North Carolina-Charlotte, Charlotte, NC 28223-0001. 
developmental period between the ages of 18 and 25, emerging adulthood is a period of identity exploration, instability, self-focus, transition, and possibilities. Unfortunately, it is also a period when the probability of offending and being victimized peaks for a number of different crimes (Piquero, Brame, Mazerolle, \& Hapaanen, 2002; see also Fisher, Cullen, \& Turner, 2000 , for increased risk of being sexually victimized).

Over the past two decades, understanding the nature and extent of the sexual victimization experiences of college students within the period of emerging adulthood has captured the interests of several researchers (DeKeseredy \& Kelly, 1993; Fisher et al., 2000; Koss, Gidycz, \& Wisniewski, 1987). Recognizing that college campuses are not immune to crime and that the true levels of sexual victimization are unknown, Koss and her colleagues (1987) initiated the first national effort to shed light on the nature and extent of sexual victimization of female college students. More than a decade later, and following a similar methodology, Fisher and her colleagues (2000) collected sexual victimization data from a second national sample of female college students. Despite minor differences in methodological approaches, each of these national studies documented the measurement issues surrounding the nature and extent of sexual victimizations that occur on college campuses. In fact, these studies indicated that sexual victimizations on college campuses are much more prevalent than official statistics suggest. The ubiquitous impact of this research inevitably has initiated a number of other campus-specific studies investigating the victimization experiences of college students (see CombsLane \& Smith, 2002; Kalof, 2000; Larimer, Lydum, Anderson, \& Turner, 1999; Parks \& Fals-Stewart, 2004).

One type of sexual victimization experienced by individuals during emerging adulthood that has received significant attention within the research community has been sexual harassment (Cortina, Swan, Fitzgerald, \& Waldo, 1998; Menard, Hall, Phung, Ghebrial, \& Martin, 2003). In a review of more than 120 studies, Spitzberg (1999) found that sexual harassment has a higher prevalence rate than more physically violent sexual assaults. Despite the scholarly attention that sexual harassment has drawn, few studies have investigated the impact that theoretical models possess in empirically explaining this behavior (for an exception, see Fisher, et al., 2000). Moreover, even fewer studies have examined the impact of competing theories on the explanation of sexual harassment incidents.

The current study seeks to fill this void in the campus victimization literature. Using a randomly selected sample of students from a medium-sized southeastern university, we address a number of questions related to the sexual harassment experiences of college students. To guide our analyses, we 
use tenets of routine activities theory and the general theory of crime to test a number of hypotheses (see Cohen \& Felson, 1979; Gottfredson \& Hirschi, 1990). First, we examine the nature and extent of three types of sexual harassment (physical, verbal, and nonverbal) on a college campus. Second, we investigate the prevalence rate of reporting and the potential reasons students fail to report. Third, we investigate whether measures of routine activities theory and the general theory of crime effectively explain sexual harassment. Before embarking on these analyses, we present the literature related to sexual harassment and the theories guiding our research.

\section{Literature Overview}

Sexual harassment is a form of sexual victimization historically associated with the workplace (LaRocca \& Kromrey, 1999; Rubin, 1995), and its definition has been the topic of continual modification since its inception (Birdeau, Somers, \& Lenihan, 2005; Fitzgerald, Swan, \& O’Donohue, 1997). However, sexual harassment occurs in many different venues, including academic environments, and has been documented as a pervasive problem (Bradenburg, 1997; Dansky \& Kilpatrick, 1997; Dziech, 2003; Dziech \& Hawkins, 1998; Hall, Graham, \& Hoover, 2004; Paludi, 1997; Williams, Lam, \& Shively, 1992). Approximately $50 \%$ of all women who were ever employed, and about $30 \%$ of all women who attended 4-year colleges, report being sexually harassed (Dansky \& Kilpatrick, 1997; Paludi, 1997). Dziech (2003) reported that university faculty members have victimized approximately $30 \%$ of undergraduate females and $40 \%$ of female graduate students, whereas $90 \%$ of undergraduate females reported unwanted behavior from their male peers. However, these estimates may not accurately represent the true rate of victimization because of the general consensus that individuals of differing races and genders perceive, label, and report sexual harassment differently (Birdeau et al., 2005; Fitzgerald \& Ormerod, 1991; Ivy \& Hamlet, 1996; Kalof, Eby, Matheson, \& Kroska, 2001; Kelley \& Parsons, 2000; Magley \& Shupe, 2005; Shelton \& Chavous, 1999). For example, research suggests that sexual harassment is more likely to occur among certain populations including females, graduate students, women in nontraditional fields, minority females, disabled persons, divorced women, young and naïve females, persons who were sexually abused, and homosexuals (Cortina et al., 1998; Dziech, 2003; Kalof et al., 2001; Paludi, 1997; Russell \& Oswald, 2001). Related research observes that particular interactions may enhance a student's risk of sexual harassment victimization such as being in an environment that includes alcohol (Collins \& 
Messerschmidt, 1993; Gover, 2004), having a one-on-one relationship with a person of direct authority, or participation in group activities (Bradenburg, 1997). Consequently, when a victim disengages from his or her academic endeavors, the harassing behavior of the offender can be reinforced (Benson \& Thomson, 1982; Schneider, 1987).

\section{Reporting Victimization on College Campuses}

Even though the overwhelming majority of crimes "known to the police" are made through citizen reports (Reiss, 1971; Visher, 1983), many victims do not report their experience (Tjaden \& Thoennes, 2000). Research has found that personal crimes involving college students are often drastically underreported. In fact, some research suggests that only $25 \%$ of all campus crimes are reported to the authorities (Fisher, Sloan, Cullen, \& Lu, 1998). Compounding the reporting problem, studies indicate that of those personal crimes that are reported, some college campuses are not well equipped to address the challenges with processing these offenses (Fisher, Hartman, Cullen, \& Turner, 2002).

Whereas Fisher and her colleagues provided much-needed insight surrounding campus sexual victimization, there has been minimal information concerning the reporting practices of sexual harassment on college campuses. Clearly, the decision to disclose a personal crime rests primarily with the victim; however, certain known reporting characteristics are relevant on this front. Discovering why a sexual harassment victim might not disclose the incident to campus authorities is important to improving our understanding and responding to these categories of crime. Past research identifies several possible reasons for underreporting.

Self-blame. Although most crime victims absolve themselves of responsibility for event, the inverse is typically true in cases involving sexual victimization. When victims perceived that their own actions (or inactions) precipitated the event, they will be more likely to blame themselves and less likely to report the incident (Fisher, Daigle, Cullen, \& Turner, 2003). Furthermore, research indicates that the presence of drugs or alcohol can mediate a victim's willingness to comply with authorities (Collins \& Messerschmidt, 1993; although see Rickert, Wiemann, \& Vaughan, 2005, who suggest that the victim-offender relationship has a stronger influence).

Systemic factors to reporting. Attitudes among those to whom the incident would be reported can influence how and whether the victim will proceed. Several studies have linked victim nonreporting to concerns regarding systemic bias. Informed by the domestic violence research, victims often 
feel as if they are in a no-win situation; if the legal gatekeepers (e.g., police and prosecution or campus officials) do not take victims' situations seriously and there is limited tangible evidence, reporting is less likely to occur (Belknap \& Hartman, 2003; Gillis et al., 2006; Koss, 2000).

In lieu of reporting to an official agency, victims may be inclined to report the incident to others (Fisher et al., 2003; Rickert et al., 2005). Historically, juvenile crime victims were more likely to disclose the incident to someone outside of the criminal justice system (Finkelhor \& Ormond, 2001), whereas Dunn, Vail-Smith, and Knight (1999) found that approximately one third of college respondents reported their sexual assault to a peer. Of note, those women who confided in a friend did not tell family or service providers.

Incident seriousness. How serious a victim perceives the event to be may influence his or her willingness to report. The sexual assault/rape literature indicates that some victims do not label their experience as a rape because the assault did not fit into their individual definition of the crime (Littleton, Axsom, \& Yoder, 2006) or because the victim downgrades the event as a miscommunication versus an assault (Littleton, Axsom, Breitkopf, \& Berenson, 2006). Such misperceptions are certainly likely within a sexual harassment context.

Victim-offender relationship. Although disclosure of a personal victimization has been identified as an important step toward recovery, research on females in emerging adulthood suggests that sexual assault victims often do not disclose, especially if the victim knows the assailant. In their study on estimating disclosure rates of date/acquaintance rape, Rickert et al. (2005) found that victims were more likely to report the incident if the perpetrator was not a current boyfriend or partner (although see Goudriaan \& Nieuwbeerta, 2007, who found that willingness to report to the authorities was influenced by whether the victim knew the offender or whether the victim was part of the same organization as the offender).

Despite these measurement and reporting concerns, there remains an opportunity to learn more about what influences and explains sexually harassing behavior. Borrowing evidence from other types of personal victimizations allows researchers to build from a foundation of knowledge and explore their connection with sexual harassment. Often these types of victimizations overlap in definitions. For example, some campus sexual harassment policies include coerced sexual intercourse and unwanted attempted or actual fondling, which may be defined as sexual assault. Therefore, measurement and reporting concerns are likely to be similar for sexual harassment victimization. Although this research will address some 
of these important measurement challenges, it will also attempt to test the impact of two different theoretical models-routine activities and selfcontrol-as discussed below.

\section{Routine Activities Theory}

Cohen and Felson (1979) contended that the convergence in time and space of a motivated offender, suitable target, and lack of capable guardianship is conducive to criminal offending (also see Clarke \& Felson, 1993; Felson \& Clarke, 1998). Routine activities explanations were traditionally applied to crimes such as property, but a review of victimization literature suggested that routine activities theory might also be used to account for personal victimization. Mustaine and Tewksbury (1999) reported that activities that placed college women in closer proximity to offenders and actions that reduced their guardianship led to a greater risk of stalking victimization. Fisher, Cullen, and Turner (2002) also explored stalking among college students and determined that factors such as frequenting a place where alcohol was served, living alone, being involved in dating relationships, and prior victimization were significantly related to further victimization. Other research has shown that risky behaviors including drug and alcohol abuse were predictive of dating violence and sexual victimization (Felson \& Burchfield, 2004; Gover, 2004; Wilson, Calhoun, \& McNair, 2002). That is, substance abuse may decrease a victim's personal guardianship, particularly while in proximity to a motivated offender, thus increasing the likelihood of becoming a suitable target.

\section{Sexual Harassment and Routine Activities Theory}

Routine activities theory can be specifically applied to the study of sexual harassment in an academic setting for several reasons. The certain types of individuals at risk for victimization, females in particular, represent the majority of undergraduate and graduate student enrollment (Dziech, 2003; Paludi, 1997; U.S. Department of Education, 2007). Meanwhile, individuals tend to reach their criminal-offending peak in their late teens and begin to desist in their early 20s (Moffitt, 2003), and offenders are predominantly male (Cohen \& Vila, 1996; Menard et al., 2003). Therefore, one can reasonably conclude that combining males, who are most prone to committing offenses during their college-age years, with females, who dominate campus student populations, has the potential to increase opportunities for victimization. 
Cohen and Felson (1979) suggested that the victim (target) must be perceived as suitable by the offender, which may be because of the proximity of the victim to the offender or the lack of guardianship of the victim. Both of these situations occur regularly on college campuses. Males and females share space such as classrooms, dormitories, and cafeterias. Many classes are held at night, and consequently students walk (sometimes alone) to their cars, dorms, parking garages, or residences after dark.

Alcohol consumption is a significant factor that places individuals at risk of sexual harassment victimization (Abbey, Zawacki, Buck, Clinton, \& McAuslan, 2001; Rothman \& Silverman, 2007). Campus research indicates that high rates of male and female college students engage in binge drinking and other serious levels of alcohol consumption (Leppel, 2006; Weitzman $\&$ Nelson, 2004). From a perspective of routine activities, intoxication can lower the ability to protect oneself from victimization and accurately perceive dangerousness. In fact, Menard et al. (2003) found alcohol to be a significant predictor of male-perpetrated harassment and coercion and female-perpetrated harassment.

The social and structural natures of college campuses shape the routine activities of individuals, which may increase the risk for sexual harassment victimization. Students regularly interact with potential offenders in settings that increase the opportunities for offending. Also, college students are likely to engage in behaviors that lower their ability to safeguard themselves against potential offenders. Finally, students may lack guardianship when engaging in normal campus behaviors such as traveling alone or studying in private areas.

\section{General Theory of Crime}

Self-control theory, or the general theory of crime, attempts to explain all individual differences (sex, culture, age, and circumstance) in the propensity to commit or to refrain from committing crime and analogous behaviors (Gottfredson \& Hirschi, 1990) and has been found to be one of the strongest predictors of such behaviors (see Pratt \& Cullen, 2000). The premise of the theory is that individuals with low self-control (LSC) will be at an increased risk for involvement in criminal and analogous behavior. These behaviors may be defined among similar groups of people and may remain stable throughout the life course (Gottfredson \& Hirschi, 2003).

More recent studies have applied the theory to victimization, and significant findings have emerged. Schreck (1999) suggested that when an individual lacks the attributes of self-control, a vulnerable situation emerges in which the individual can place himself or herself at risk. Schreck found that 
males were more likely than females to be victimized, and females with LSC were at a greater risk of victimization than females with high selfcontrol. Also, victims who reported lower levels of self-control and risky lifestyles also reported a higher number of criminal offenses. Stewart, Elifson, and Sterk (2004) furthered Schreck's study to determine whether LSC could account for variations in violent victimization and whether risky lifestyles mediated the effect of self-control as an explanation of victimization among female offenders. The findings of Stewart et al. supported the hypothesis that women with LSC were more likely to be violently victimized, regardless of demographics or routine activities.

\section{Sexual Harassment and the General Theory of Crime}

Using the general theory of crime to explain sexual harassment in an academic setting is appropriate for a variety of reasons. Many attributes of self-control (see Shreck, 1999) are expected to be present among individuals who are considered to have high levels of self-control. However, not all individuals who are enrolled in higher education institutions can be presumed to possess these qualities, thus creating an expectation of varied levels of self-control.

Although it is theorized that individuals with LSC are more likely to engage in risky behaviors, these behaviors may not directly contribute to one's risk of victimization. It can be argued, however, that engaging in risky behaviors with others who are also engaging in risky activities may increase one's vulnerability. Thus, an overlap may exist among victims and offenders. For example, victimization frequently occurs while students are participating in socially acceptable behaviors including risky activities and events involving alcohol (Bradenburg, 1997). Binge drinking is a major concern for college campuses (Gibson, Schreck, \& Miller, 2004) because individuals who engage in such activities may be at a greater risk of victimization because of the vulnerabilities created by these environments. Students may not possess sufficient self-controls that might protect them from engaging in behaviors that may lead to victimization. This theoretical perspective is not intended to place blame on victims; rather, its purpose is to highlight factors that are associated with increased risk of victimization.

It is important to remember, however, that sexual harassment may occur without the overlap of victim and offender characteristics. For example, being a member of a previously defined vulnerable population does not imply that a person inevitably possesses LSC. Also, a person may be a victim of sexual harassment without having any type of relationship with the offender. 
Ultimately, one primary purpose of this research is to determine whether the level of self-control contributes to the risk of sexual harassment victimization.

\section{Summary and Current Focus}

Although sexual harassment has often been the focus of research in the workplace, understanding and preventing offending and victimization patterns among emerging adults are particularly important on college campuses because these experiences can result in adverse academic outcomes and high rates of physical and psychological injury. Sexual harassment on college campuses is currently understudied and underreported but also likely to be prevalent. College campuses naturally bring motivated offenders into close proximity with suitable targets, often in the absence of capable guardians. Typical emerging adult behaviors that peak during college years include frequent and increased alcohol consumption, illicit drug experimentation and use (U.S. Department of Health and Human Services, 2006), and periods of freedom mixed with solitude, all of which may increase risky behavior and affect individual levels of self-control. As a result, continued study of sexual harassment prevalence, variations, and theoretical explanations on campus remains important. Using an online survey design, this research contributes to the scholarly literature regarding the nature and prevalence of sexual harassment, the characteristics of victims and offenders, and two theoretical models for explaining the circumstances under which sexual harassment is most likely to occur.

\section{Methods}

\section{Sample}

Participants comprised a random sample of 750 college students. Participant names were generated from the eligible campus population of a southeastern urban university. Eligibility included being enrolled during the fall semester of 2004. The target population either had assigned e-mail accounts that were provided by the university or had alternate e-mail addresses stored within the contact information provided to the school. E-mail addresses were used to initiate correspondence. All students first received a letter via electronic mail to introduce them to the study. A second letter was sent 2 weeks later with a link to a Web site that would host the survey. Two follow-up requests were e-mailed within 3-week intervals for those who did 
not initially respond. Once a student agreed to participate, he or she was directly routed to the Web address that housed the self-administered questionnaire. The survey was available from March 2005 through April 2005. Completion time ranged from 5 to 30 minutes Survey directions prompted respondents to recall events between the 2004 fall semester and the end of March of the 2005 spring semester.

The challenges associated with Internet-based research (Hine, 2005) and with using online survey methods have been identified in methodological research (Dillman, 1999). In this study, the eligible participants had regular access to campus computers and each student had a university-assigned e-mail account. This ensured that all students had an opportunity to be randomly selected for the study. The survey itself was designed for those with minimal computer literacy skills to ensure comprehension and completion and to discourage lack of computer savvy as an exclusion factor. In summary, the survey methodology was designed to maximize participation and was appropriate for the study purpose and target population.

Online survey methodologies are relatively new to the social sciences. Historically, response rates of at least 50\% for other types of surveys (mail, fax, hand-delivered, etc.) were considered adequate for analytical purposes (see Dillman, 1999). However, some evidence suggests that response rates for online surveys might be systematically lower and may decrease over time. For example, Sheehan (2001) found that response rates to e-mailed surveys from 1991 to 1996 averaged $46.8 \%$ but decreased to $29.5 \%$ from 1997 to 2000. Hamilton (2003) reported wide variation in response rates at one online survey Web site, where half of the surveys generated at least a $26 \%$ response rate, the average response rate was $32.5 \%$, and smaller, targeted surveys tended to generate slightly higher response rates. Brown (2005) found no significant differences between e-mailed surveys or online-based protocols.

In the present study, 216 students (29\%) started and completed most of the survey, although some intrasurvey attrition and missing data resulted in 164 completed surveys (22\%). ${ }^{1}$ This response rate appears to be fairly consistent with online survey response rates. Furthermore, the sample fairly closely approximated the university population of interest with some minor exceptions (see Table 1), and missing data analyses and alternative multivariate models suggested that the respondents who completed the survey were not significantly different from those who did not. ${ }^{2}$

The study sample included significantly more females (65\% vs. $55 \%)$ and Whites ( $83 \%$ vs. $75 \%$ ) than the overall campus population. ${ }^{3}$ In terms of class standing, the largest proportion of students who completed the survey were seniors (27\%, compared with $22 \%$ across the university) with juniors (26\% vs. 


\section{Table 1}

\section{Descriptive Statistics of Sample Population and Victim Population}

\begin{tabular}{|c|c|c|c|c|}
\hline Variable & $\begin{array}{c}\text { Sample } \\
\%\end{array}$ & $\begin{array}{c}\text { Campus } \\
\%\end{array}$ & $\begin{array}{c}\text { Victim, } \\
n(\%)\end{array}$ & $\begin{array}{c}\text { Nonvictim, } \\
n(\%)\end{array}$ \\
\hline \multicolumn{5}{|l|}{ Sex } \\
\hline Female & 65 & 55.3 & $18(85.7)$ & $88(62.0)$ \\
\hline Male & 35 & 44.7 & $3(14.3)$ & $54(38.0)$ \\
\hline \multicolumn{5}{|l|}{ Race } \\
\hline White & 83.5 & 74.8 & $19(90.4)$ & $118(83.0)$ \\
\hline Non-White & 16.5 & 25.2 & $2(9.6)$ & $25(17.0)$ \\
\hline \multicolumn{5}{|l|}{ Class } \\
\hline Freshman & 6.7 & 19.6 & NA & NA \\
\hline Sophomore & 15.9 & 17.1 & NA & NA \\
\hline Junior & 25.6 & 19.0 & NA & NA \\
\hline Senior & 26.8 & 22.3 & NA & NA \\
\hline Undergraduate special & NA & 2.0 & NA & NA \\
\hline Graduate/doctoral & 25.0 & 20.0 & NA & NA \\
\hline \multicolumn{5}{|l|}{ Age, years } \\
\hline Average age & 25.5 & 25.2 & NA & NA \\
\hline $18-25$ & NA & NA & $19(90.4)$ & $95(66.9)$ \\
\hline $26-35$ & NA & NA & $1(4.8)$ & $28(19.7)$ \\
\hline $36+$ & NA & NA & $1(4.8)$ & $19(13.4)$ \\
\hline \multicolumn{5}{|l|}{ Enrollment status } \\
\hline Full time & 74.7 & 69.3 & NA & NA \\
\hline Part time & 25.3 & 30.7 & NA & NA \\
\hline \multicolumn{5}{|l|}{ Location of residence } \\
\hline On campus & 22.2 & 21.3 & NA & NA \\
\hline Off campus & 77.8 & 78.7 & NA & NA \\
\hline \multicolumn{5}{|l|}{ Sexual orientation } \\
\hline Heterosexual & NA & NA & $18(85.7)$ & $139(97.9)$ \\
\hline Homosexual & NA & NA & $3(14.3)$ & $3(2.1)$ \\
\hline \multicolumn{5}{|c|}{ Prior campus sexual harassment } \\
\hline Yes & NA & NA & $10(47.6)$ & $6(4.2)$ \\
\hline No & NA & NA & $11(52.4)$ & $136(95.8)$ \\
\hline
\end{tabular}

Note: Comparison of the sample population and campus population revealed statistically significant differences for race and class at $p<.05$. Between victims and nonvictims, age and sex were statistically significant at $p<.05$, whereas sexual orientation and prior campus sexual harassment differences emerged at $p<.01 . \mathrm{NA}=$ not available.

$19 \%$ ) and graduate students (25\% vs. $20 \%$ ) nearly equally represented. ${ }^{4}$ The most underrepresented group was freshmen (6.7\% vs. 19.74\%). The modal age (17\%) of participants was 21 years, and the mean age (25.4 years) closely approximated the university average student age (25.2 years). Nearly $75 \%$ of 
the students were classified as full-time students compared with $69 \%$ across the university. Nearly all of the respondents reported being heterosexual (96\%) and 59\% lived with roommates, whether on campus or off campus. The sample population reasonably represented the overall campus population, with minority students slightly underrepresented and females, full-time students, upper class students, and graduate students slightly overrepresented.

\section{Measures}

Independent variables. The primary goals of the research were to estimate the prevalence of campus-based sexual harassment, define and describe the victim and offender characteristics of those who reported victimization, and identify theoretical predictors of sexual harassment in this context. Within the study, routine activities of students were explored in an effort to measure whether the students' behaviors or actions placed them at an increased risk for sexual harassment victimization and whether their own levels of self-control increased the probability of being victimized. The specific theoretical concepts measured were (a) lack of capable guardianship, (b) proximity to offender, and (c) target suitability (routine activities) and self-control.

Capable guardianship is an index consisting of two variables: (a) whether a person carries self-protection such as pepper spray and (b) how often the person was escorted to his or her car after dark. Self-protection was coded as $1=$ carries self-protection. Escort was labeled as $1=$ never escorted to $4=$ escorted all the time. Each variable was standardized and summed to create a measure of capable guardianship, with higher scores indicating more capable guardianship. ${ }^{5}$ These measures are related to routine activities theory because the presence of self-protection or an escort may deter an offender from selecting that particular individual to victimize. Although carrying self-protection may not deter verbal and nonverbal sexual harassment incidents, it may prevent an incident of physical sexual harassment if the offender is aware that the potential victim has protection. ${ }^{6}$

Proximity to offenders is a five-item index that captures the enrollment status of students, whether they lived or worked on campus, whether they spent their weekends on campus, and whether they participated in campus activities (alpha $=.52$ ). Enrollment status was coded as $0=$ part time and $1=$ full time. The other variables were coded as $1=y e s$. The answers for these five questions were summed to create the proximity measure. Each of these items was chosen to indicate whether the normal activities of a student that placed him or her among potential offenders increased his or her risk of being victimized. 
An individual perceived to be more vulnerable to victimization by a motivated offender was classified as a suitable target. Target suitability is a two-item measure that documents how likely a person was to find a private place to eat and study. The options were labeled as $1=$ least likely to find $a$ private place, $2=$ less likely to find a private place, $3=$ likely to find a private place, $4=$ more likely to find a private place, and $5=$ most likely to find a private place. Higher scores are indicative of being a more suitable target to potential offenders. Seeking privacy may isolate a victim from capable guardianship and make him or her more attractive as a target. The reliability of the measure was moderate (alpha $=.62$ ).

Self-control was measured by using a scale containing six questions regarding one's perception of his or her own self-control (see Turner \& Piquero, 2002). The questions assessed (a) whether a person gets into a jam because he or she does things without thinking, (b) whether he or she thinks planning takes the fun out of things, (c) whether he or she has to use a lot of self-control to keep out of trouble, (d) whether he or she enjoys taking risks, (e) whether he or she enjoys a new and exciting experience, even if it is a little frightening or unusual, and (f) whether life with no danger would be too dull for him or her (alpha $=.71)$. Response sets were labeled as $1=$ strongly disagree to $4=$ strongly agree. The scale scores ranged from 6 to 24, with higher scores being indicative of lower levels of self-control.

Control variables. Prior research suggests that individuals of different races and genders perceive and label sexual harassment differently (Birdeau et al., 2005; Fitzgerald \& Ormerod, 1991; Magley \& Shupe, 2005; Shelton \& Chavous, 1999) and that sexual harassment victimization might be more likely to occur among certain subpopulations (Cortina et al., 1998; Dziech, 2003; Paludi, 1997; Russell \& Oswald, 2001). Therefore, several control variables were included, such as age (measured continuously in years), sex $(1=$ female $)$, race $(1=$ non-White $)$, sexual orientation $(1=$ heterosexual $)$, and prior sexual harassment victimization on campus $(1=y e s)$.

Dependent variables. The dependent variables were physical sexual harassment, nonverbal sexual harassment, and verbal sexual harassment. The definitions used for each type of sexual harassment were selected from the Prevention Brochure of Sexual Harassment, previously published by the university under analysis. ${ }^{7}$ Physical sexual harassment is defined as patting, pinching, tickling, or other unwanted touching; brushing against the body; attempted or actual kissing; attempted or actual fondling; or coerced sexual intercourse. Nonverbal sexual harassment is defined as public display or sharing of pictures or photographs of a sexual nature; e-mails or Web sites of a sexual nature; love notes or letters; suggestive comments on memos; graffiti; 
or gag gifts such as sex toys or games. Verbal sexual harassment included sexual innuendoes and comments; whistling in a suggestive manner; jokes about sex or gender in general; spreading rumors about sexual activity or performance of a student or employee; sexual propositions, invitations, or other pressures for sex; or implied or overt threats. Each of these variables were coded as $1=$ experienced sexual harassment. An overall indicator of sexual harassment was also tested by asking whether a participant answered yes to any of the specific harassment questions.

\section{Findings}

The majority of the victims and nonvictims (see Table 1) were within the age range of 18 to 25 years. Both groups were overwhelmingly female, White, and heterosexual. ${ }^{8}$ However, among victims, nearly half had previously been sexually harassed on campus, and only a small percentage of nonvictims had previously been sexually harassed on campus. ${ }^{9}$

We begin by reporting the prevalence rate of sexual harassment victimization. The data indicated that $22.7 \%$ of the participants were victims of sexual harassment during the study time. More specifically, $7.0 \%$ experienced a physical sexual harassment, $7.0 \%$ experienced a nonverbal sexual harassment, and $14.5 \%$ experienced a verbal sexual harassment. ${ }^{10}$ As shown in Table 2, whereas more than nine tenths $(92.9 \%)$ of the perceived offenders were other students, half (50.0\%) were also strangers. As such, unlike more serious forms of sexual assaults on emerging adults where victims and offenders are typically acquaintances, offenders who sexually harass on campus were more likely to be strangers.

Table 2 also indicates that offenders were generally male (70.8\%), were usually White (62.5\%), and typically offended in isolation when they harassed their victims (62.5\%). In terms of the location of the incident, most offenders chose to victimize students within a classroom building or lab $(25.0 \%)$, outside but near campus living quarters (20.8\%), or outside or near a classroom building or gym (16.7\%). Most respondents who were victimized were alone during the incident $(66.7 \%)$ but did not consume alcohol prior to or during the incident $(95.8 \%)$. This last finding is significant given the lengthy literature that has documented the prevalence of alcohol during more serious types of sexual victimization of this population (Fisher et al., 2000; Testa \& Parks, 1996). In fact, the data from the present study suggest the opposite in that almost all of the sexual harassment incidents on campus occurred without the victim consuming alcohol. 
Table 2

Characteristics of Sexual Harassment Offender, Incident, and Reporting

Characteristic

Type of offender

Student

Both student and employee

Association with offender

Stranger

50.0

Acquaintance

25.0

Classmate

10.7

Friend

Number of offenders

One

More than one

Sex of offender

All female

All male

70.8

Both

25.0

Perceived race/ethnicity of offender

White

Non-White

Perceived age of offender, years

18-24

36 and above

Location of offense

Inside your campus living quarters

Outside, but near your campus living quarters

Specifically designated parking lot, parking area

Another campus living quarter

Classroom, building, or lab

Gym

Dining area

General parking lot or area

Outside or near classroom building, library, gym

Other

Alone during offense

Yes

No

Consumed alcohol during offense

Yes

No 
Table 3

Characteristic of Reporting Incidents

\begin{tabular}{lrr}
\hline Characteristic & $\%$ & $n$ \\
\hline Victim reported incident to university officials & & \\
$\quad$ No & 100.0 & 24 \\
Reasons victim did not report & 12.5 & 3 \\
$\quad$ Lack of poof that incident happened & 12.5 & 3 \\
$\quad$ Not clear it was sexual harassment or that harm was intended & 4.2 & 1 \\
Did not know how to report & 4.1 & 1 \\
Felt officials would not think it was serious & 66.7 & 16 \\
Did not think it was serious enough to report & & \\
Discussed victimization with a person who was not a university official & 62.5 & 15 \\
Yes & 37.5 & 9 \\
No & & \\
Nonuniversity official encouraged victim to report & 4.2 & 1 \\
Yes & 95.8 & 23 \\
No & & \\
Victim wanted to report & 12.5 & 3 \\
$\quad$ Yes & 87.5 & 21 \\
$\quad$ No & & \\
\hline
\end{tabular}

\section{Characteristics Related to Reporting Sexual Harassment Incidents}

Table 3 provides the results on the nature and extent of reporting sexual harassment incidents. ${ }^{11}$ To begin, none of the respondents who were sexually harassed reported the incident to university officials. This finding could potentially make sense for two thirds of the respondents, who did not feel that the incident was serious enough to warrant reporting to a university official. Conversely, roughly one third (33.3\%) of the respondents did think the incident was serious enough to report, but elected not to complete a formal report. Also identified in Table 3, 62.5\% of those victimized felt that the incident was serious enough to discuss it with someone other than a campus authority figure. In nearly all cases $(95.8 \%)$ when the victim did discuss the incident with someone other than a campus official, he or she was not encouraged to report the incident. Notably, $12.5 \%$ of the victims wanted to report the incident to university officials. Together, the latter findings might suggest that students do not know how to report a sexual harassment incident or are simply not reporting. We return to this point in our later discussion. 


\section{Investigation of the Sources of Sexual Harassment}

The final interest of this study is to investigate the predictors of sexual harassment. Table 4 reports the results of three logistic regressions predicting sexual harassment. Specifically, in Model 1 a set of demographic predictors were regressed on the measure of sexual harassment; in Model 2 the measure of self-control was added; and in Model 3 the routine activities measures were added.

Beginning with Model 1, the results indicate that experiencing prior sexual harassment $(b=3.04 ; p=.00)$ significantly increased the odds of experiencing subsequent sexual harassment. Inclusion of the self-control measure in Model 2 did not change the significance of the control variables. That is, a prior sexual harassment $(b=3.07 ; p=.00)$ still significantly increases the odds of experiencing a subsequent sexual harassment. The addition of the self-control measure, however, did not emerge as a significant predictor of sexual harassment. Finally, in Model 3, age $(\mathrm{b}=-.33 ; p=.05)$ emerged as a significant predictor, suggesting that older students were less likely to be victimized. Prior sexual harassment $(b=5.28 ; p=.00)$ continued to increase the chances of additional victimization. Sexual orientation $(\mathrm{b}=-8.37 ; p=.05)$ and race $(\mathrm{b}=-2.72 ; p=.05)$ emerged as significant predictors in the final model. Although the measure of self-control was unrelated to sexual harassment, the guardianship $(\mathrm{b}=-0.95 ; p=.01)$ and proximity measures $(\mathrm{b}=1.20 ; p=.00)$ each independently emerged as significant predictors. Specifically, individuals with increased levels of guardianship were less likely to experience sexual harassment, whereas individuals who spent more time on campus and were more proximate to potential offenders were more likely to be victimized.

\section{Discussion}

Emerging adulthood has been documented as a period of substantial transition and exploration (Arnett, 2000, 2004). Understanding the nature and extent of victimization experiences within this period has attracted the attention of scholars. Much of this attention has focused on sexually related or sexually explicit offenses (Fisher et al., 2000). The present study contributes to this literature by documenting the nature and extent of sexual harassment victimizations of a sample of predominantly emerging adults, providing an indepth exploration of the reporting characteristics of sexual harassment victims, and investigating the theoretical factors related to the probability of being sexually harassed. Three key findings emerged from these efforts. 


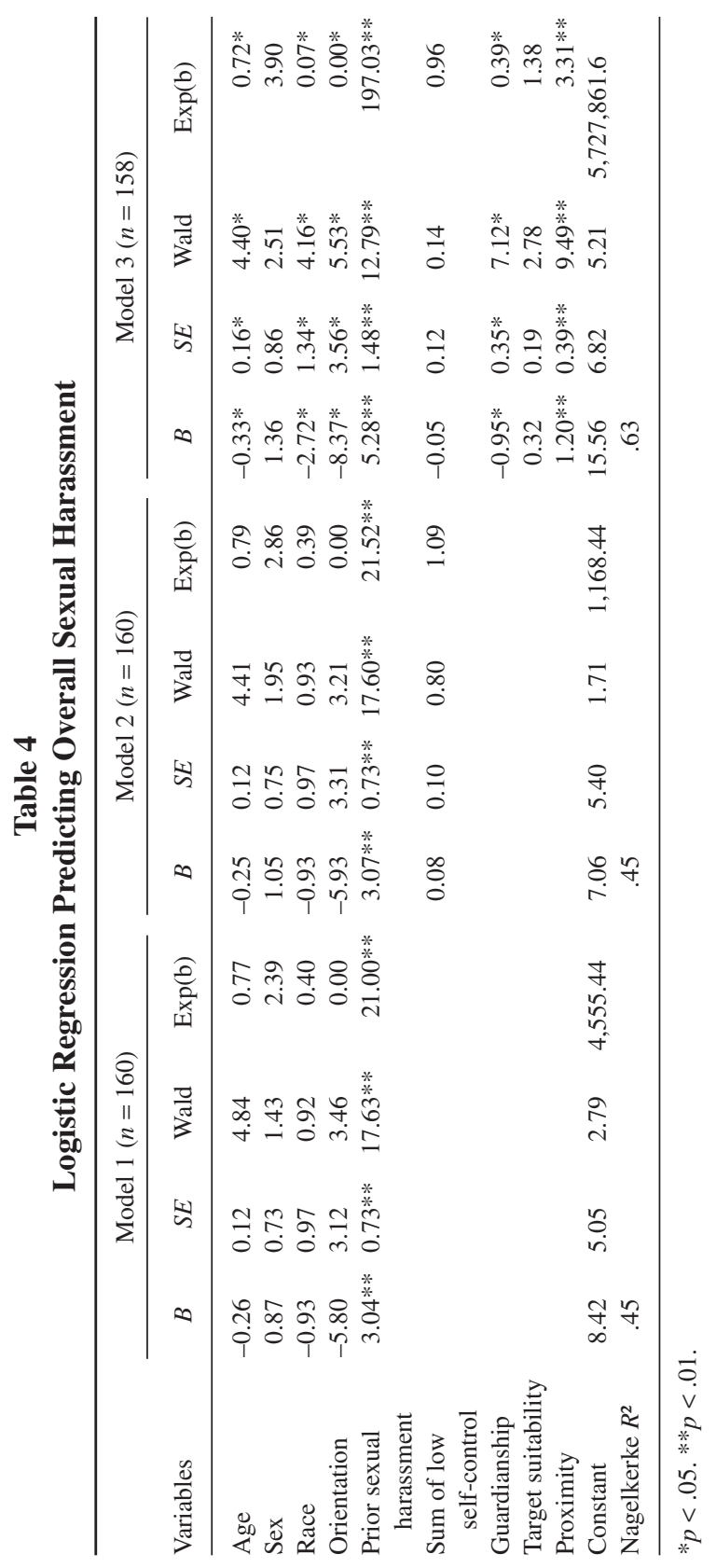


First, just less than one fourth (22.7\%) of our sample reported experiencing some type of sexual harassment (i.e., verbal, nonverbal, or physical) since school began during that academic year. This suggests that in any given academic year, 2,270 students on a campus with a population of 10,000 students might expect to experience sexual harassment. If prevalence rates in our study are similar to those occurring at other college campuses, these figures would imply that there would be approximately 700 incidents of physical sexual harassment, 700 incidents of nonverbal sexual harassment, and 1,450 incidents of verbal sexual harassment. Depending on the nature of the incident, these figures are cause for increased concern considering how sexual harassment affects the well-being of the student throughout his or her academic career (Fisher et al., 2002).

Second, this research provided insight into the context in which victims of sexual harassment report, or in this case fail to report, being sexually harassed. As highlighted above, although $12.5 \%$ of victims wanted to report the incident to university officials, not one victim actually reported the incident to an official agency. This figure might make sense to the casual observer who points to data suggesting that approximately two thirds of the victims did not think their experience was serious enough to warrant being reported to campus authorities. In other words, some might question whether a sexual harassment incident actually occurred in approximately two thirds of the cases. We caution readers to also consider one additional piece of information before drawing any definitive conclusions. Specifically, almost two thirds $(62.5 \%)$ of the victims also discussed the incident with an individual who was not connected to the university. Stated differently, almost two thirds of the victims felt the incident was serious enough to discuss it with someone, but in the end they were reluctant to do so with university officials (see Belknap \& Hartman, 2003). Future research efforts should elaborate on the factors that influence victims' reporting practices in sexual harassment incidents.

Third, the results of the multivariate models indicated that two measures of routine activities (proximity and guardianship) were significantly related to experiencing sexual harassment whereas the measure of self-control was not significant. Specifically, respondents who were more proximate to motivated offenders by having a greater presence on campus were more likely to experience sexual harassment. On the other hand, respondents who used strategies to increase their level of guardianship were less likely to be sexually harassed. Together, these findings confirm prior research efforts that sought to understand sexually related victimizations from a routine activities perspective (Fisher et al., 2000).

It was somewhat surprising that the self-control measure failed to emerge as a significant predictor of sexual harassment given that this variable has 
been identified as one of the strongest predictors of crime and victimization (see Pratt \& Cullen, 2000). A few potential explanations are offered. First, it might be the case that college students possess relatively high levels of selfcontrol. In fact, a comparison of identical self-control scales within our present study (mean $=13.10 ; S D=3.261$ ) and the National Longitudinal Survey of Youth (mean $=14.92 ; S D=2.74)$ from which the measures were derived (see Turner \& Piquero, 2002) supported these assertions. Second, and related, this study only used a six-item measure of self-control. Although this measure has been used in previous research, it still may have not captured enough variation within a population of college students. Third, it might be the case that an individual's self-control has little to do with his or her likelihood of being sexually harassed. Again, although prior research suggests that self-control was related to victimization (see Schreck, 1999; Unnever \& Cornell, 2003), it is possible that an individual's self-control has little to do with this specific type of victimization.

Combined, the results of the present study suggest a two-tiered approach for policies seeking to reduce the probability of sexual harassment experiences for college students. Specifically, policies should first focus on educating potential offenders and victims regarding what it means to sexually harass or to be sexually harassed. It is important that both males and females receive such education to ensure that all students are equally aware of the definition of sexual harassment and situational contexts in which these behaviors are likely to occur. Second, policies should focus on empowering victims to be comfortable with reporting sexual harassment incidences to university authorities without fear of retaliation or other related consequences. Campus authorities can only mobilize interventions if they are aware that a problem exists. In the present research, none of the incidents were reported to campus authorities. As such, it would be difficult for administrators to understand that a problem exists and unlikely that interventions could be developed. If implemented effectively, this two-tiered approach would provide the first line of defense against a serious set of behavioral problems like sexual harassment.

Although the results of this research provide insight into the nature and extent of sexual harassment, the results must be taken within the context of the limitations of the research. First, as previously discussed, although the rate of response was comparable to other online surveys (Hamilton, 2003; Sheehan, 2001), it was not ideal. That is, although the sample was relatively similar to the campus population across many demographic items, it is unclear how generalizable our results can be because of nonresponse bias. Future researchers are encouraged to address similar hypotheses while using methodological strategies that yield higher response rates. 
Second, we investigated the effects of what we believed were two important contributors (i.e., measures of routine activities and self-control) to the explanation of sexual harassment. Other theories might be of equal or greater importance in the explanation of sexual harassment. For example, a fruitful line of research might investigate the role peers play in either modeling sexual harassment or insulating individuals from sexual harassment over the course of their lives.

Third, we examined the predictors of sexual harassment in a sample that was primarily within the developmental period of emerging adulthood. We did not, however, investigate whether the predictors of sexual harassment varied across developmental periods. For example, future research may seek to investigate whether the same predictors of sexual harassment were significant in emerging adulthood versus adulthood. It is possible that the stability brought forth with the onset of adulthood (i.e., marriage and childbearing) also adjusts the routine activities of individuals, which correspond with changes in the importance of those predictors in the explanation of sexual harassment. To provide some initial insight into this question, we examined the prevalence rates of sexual harassment across developmental periods within our sample and found that emerging adults (ages 18-25 years) experienced sexual harassment $(27 \%$ vs. $6 \% ; p<.04)$ at far greater rates than did adults (ages 26 and above). Similarly, emerging adults appeared to have significantly lower levels of self-control $(13.44$ vs. $12.20 ; p<.03)$ and significantly higher levels of guardianship (5.35 vs. $4.02 ; p<.00)$. As such, there appears to be evidence that emerging adults are qualitatively different from adults in terms of some of the predictors of sexual harassment.

Fourth, because the data were collected in a cross-sectional manner, we were (in some circumstances) unable to disentangle temporal ordering. For example, as previously discussed, we could not identify whether victims were carrying mace or other defensive mechanisms because they were concerned about being victimized or because they had already been victimized; the former is a guardianship measure whereas the latter (although still guardianship) is a response to an action. Finally, we did not include follow-up questions as to the nature of the communication that victims had with whomever they discussed the incident. This would have been relevant information because none of our victims reported their incidents to campus authorities. Given the lengthy literature on sexual assault reporting (Fisher et al., 2003), researchers investigating sexual harassment might want to focus on collecting data on the nature of these communications.

Emerging adulthood is an important developmental period because it is a time when individuals experience substantial instability, become highly 
self-focused, experience significant identity explorations, and embark on substantial transition as they approach adulthood (Arnett, 2002). Unfortunately, emerging adulthood is also a developmental period when prevalence rates of a number of risky behaviors peak, including criminal offending, victimization, alcohol use, and substance use. Sexual harassment is one of those risky behaviors that can affect subsequent routines (e.g., going to class or to work) and could also be a precursor to more serious types of victimization (e.g., sexual assault). We hope that the findings from the current study will initiate more in-depth investigations regarding the causes of risky behaviors and how the causes vary across developmental periods. Comparison of effect sizes across developmental periods would provide insight into how emerging adulthood is similar to, or qualitatively different from, the preceding and subsequent developmental periods.

\section{Notes}

1. The survey was divided into eight sections. Slight attrition (11\%) occurred between the first and second sections. Another 7\% discontinued after answering questions on their routine activities. A total of 172 students responded for personal experiences. Of the 28 victims, 24 answered the incident-specific questions. Two sections were not eligible for response, because the student answered no to the screening questions. Demographic questions were completed by $75 \%$ of the initial sample population.

2. Bivariate tests were used to determine whether the respondents who completed the survey were significantly different than the respondents who did not complete it. These analyses were conducted on the independent variables (proximity, suitable target, guardianship, and self-control) and the dependent variables measuring sexual harassment. There were no significant differences between the completed and noncompleted groups across these variables of interest, suggesting that attrition did not affect the primary variables of interest. As a second test, we reran the multivariate analyses but removed the demographic control variables because the demographics were located at the end of the survey and were affected by the attrition. Again, the results were generally very consistent, further suggesting that the impact of the intrasurvey attrition was negligible.

3. Race differences were significant at $p<.05$.

4. Class standing differences were significant at $p<.05$.

5 . Alpha $=.34$. Although the reliability coefficient is rather low by conventional standards, the measurement process may explain the result. Studies that explore the strengths and limitations of alpha as an indicator of reliability suggest that the number of items in the measure can influence alpha. For example, measures with a larger number of items may generate higher alpha scores because the number of items in the scale influences alpha, but that score does not always guarantee increased internal consistency. Conversely, measures composed of fewer items may appear to be less reliable based on alpha but that may be a function of the number of items, not the reliability of the items in the measure (Cortina, 1993; Streiner, 2003).

6 . The cross-sectional nature of our data creates a limitation with this measure. The primary reason for carrying self-protection or using an escort is unknown and could be related to previous 
campus (or off-campus) victimization experiences. However, in this cross-sectional context it is also valuable to understand whether these common forms of guardianship are related to the risk of being sexually harassed.

7. Survey questions available on request.

8. Age and sex differences were significant at $p<.05$; sexual orientation and prior campus sexual harassment were significant at $p<.01$.

9. Prior campus sexual harassment was significantly correlated with the present measure of sexual harassment $(r=.49)$.

10. These figures do not sum to the total victimization rate because individuals could have been victimized via more than one method. The total number of sexual harassment incidents was $49($ verbal $=25 ;$ physical $=12$; nonverbal $=12)$.

11. Twenty-four victims responded to the reporting questions, but 28 victims reported sexual harassment incidents.

\section{References}

Abbey, A., Zawacki, T., Buck, P. O., Clinton, A. M., \& McAuslan, P. (2001). Alcohol and sexual assault. Alcohol Research and Health, 25, 43-51.

Arnett, J. (2000). High hopes in a grim world. Youth and Society, 31, 267-286.

Arnett, J. (2002). Readings on adolescence and emerging adulthood. Upper Saddle River, NJ: Prentice Hall.

Arnett, J. (2004). Emerging adulthood: The winding road from the late teens through the twenties. New York: Oxford University Press.

Belknap, J., \& Hartman, J. L. (2003). Court professionals' self-reported attitudes about experiences with misdemeanor intimate partner violence cases. Criminal Justice and Behavior, 30, 349-373.

Benson, D. J., \& Thomson, G. E. (1982). Sexual harassment on a university campus: The confluence of authority relations, sexual interest, and gender stratification. Social Problems, 29, 236-251.

Birdeau, D. R., Somers, C. L., \& Lenihan, G. O. (2005). Effects of educational strategies on college students' identification of sexual harassment. Education, 125, 496-510.

Bradenburg, J. B. (1997). Confronting sexual harassment: What schools and colleges can do. New York: Teachers College Press.

Brown, S. L. (2005, January 1). E-mail versus Web survey response rates among health education professionals. American Journal of Health Studies. The Free Library. Retrieved November 27, 2007, from http://www.thefreelibrary.com/E-mail versus Web survey response rates among health education ....-a0152885705.

Clarke, R. V., \& Felson, M. (Eds.). (1993). Routine activity and rational choice: Advances in criminological theory (Vol. 5). New Brunswick, NJ: Transaction Books.

Cohen, L., \& Felson, M. (1979). Social change and crime rate trends: A routine activity approach. American Sociological Review, 44, 588-608.

Cohen, L. E., \& Vila, B. J. (1996). Self-control and social control: An exposition of the Gottfredson-Hirschi/Sampson-Laub debate. Studies on Crime and Crime Prevention, 5, 125-150.

Collins, J. J., \& Messerschmidt, P. M. (1993). Epidemiology of alcohol-related violence. Alcohol Health \& Research World, 17, 93-100. 
Combs-Lane, A. M., \& Smith, D. W. (2002). Risk of sexual victimization in college women: The role of behavioral intentions and risk-taking behaviors. Journal of Interpersonal Violence, 17, 165-183.

Cortina, J. M. (1993). What is coefficient alpha? An examination of theory and applications. Journal of Applied Psychology, 78, 98-104.

Cortina, L. M., Swan, S., Fitzgerald, L. F., \& Waldo, C. (1998). Sexual harassment and assault: Chilling the climate for women in academia. Psychology of Women Quarterly, 22, 419-441.

Dansky, B., \& Kilpatrick, P. (1997). Effects of sexual harassment. In W. O’Donohue (Ed.), Sexual harassment: Theory, research, and treatment (pp. 152-174). Boston: Allyn \& Bacon.

DeKeseredy, W., \& Kelly, K. (1993). The incidence and prevalence in woman abuse in Canadian university and college dating relationships. Canadian Journal of Sociology, 18, 137-159.

Dillman, D. (1999). Mail and Internet surveys: The tailored design method. New York: Wiley.

Dunn, P. C., Vail-Smith, K., \& Knight, S. M. (1999). What date/acquaintance rape victims tell others: A study of college student recipients of disclosure. Journal of American College Health, 47, 213-219.

Dziech, B. W. (2003). Sexual harassment of college campuses. In M. Paludi \& C. Paludi (Eds.), Academic and workplace sexual harassment: A handbook of cultural, social science, management, and legal perspectives (pp. 147-172). Westport, CT: Praeger.

Dziech, B. W., \& Hawkins, M. W. (1998). Sexual harassment in higher education: Reflections and new perspective. New York: Garland.

Felson, M., \& Clarke, R. V. (1998). Opportunity makes the thief (Crime Detection and Prevention Series, Paper 98, Police Research Group). London: Home Office.

Felson, R. B., \& Burchfield, K. B. (2004). Alcohol and the risk of physical and sexual assault victimization. Criminology, 42, 837-859.

Finkelhor, D., \& Ormond, R. K. (2001). Factors in the underreporting of crimes against juveniles. Child Maltreatment, 6, 219-229.

Fisher, B. S., Cullen, F. T., \& Turner, M. G. (2000). The sexual victimization of college women. Washington, DC: U.S. Department of Justice, National Institute of Justice.

Fisher, B. S., Cullen, F. T., \& Turner, M. G. (2002). Being pursued: Stalking victimization in a national study of college women. Criminology and Public Policy, 1, 257-308.

Fisher, B. S., Daigle, L. E., Cullen, F. T., \& Turner, M. G. (2003). Reporting sexual victimization to the police and others: Results from a national-level study of college women. Criminal Justice and Behavior, 30, 6-38.

Fisher, B. S., Hartman, J. L., Cullen, F. T., \& Turner, M. G. (2002). Making campuses safer for students: The "Clery Act" as a symbolic legal reform. Stetson Law Review, 32, 61-89.

Fisher, B. S., Sloan, J. J., Cullen, F. T., \& Lu, C. (1998). Crime in the ivory tower: The level and sources of student victimization. Criminology, 36, 671-710.

Fitzgerald, L. F., \& Ormerod, A. J. (1991). Perceptions of sexual harassment: The influence of gender in academic context. Psychology of Women Quarterly, 15, 281-294.

Fitzgerald, L., Swan, S., \& O’Donohue, W. (1997). But was it really sexual harassment? Legal, behavioral, and psychological definitions of the workplace victimization of women. In W. O'Donohue (Ed.), Sexual harassment: Theory, research, and treatment (pp. 5-28). Boston: Allyn \& Bacon.

Gibson, C., Schreck, C. J., \& Miller, M. (2004). Binge drinking and negative alcohol-related behaviors: A test of self-control theory. Journal of Criminal Justice, 32, 411-420.

Gillis, J. R., Diamond, S. L., Jebely, P., Orekhovsky, V., Ostovich, E. M., MacIsaac, K., et al. (2006). Systemic obstacles to battered women's participation in the judicial system when will the status quo change? Violence Against Women, 12, 1150-1168. 
Gottfredson, M., \& Hirschi, T. (1990). A general theory of crime. Palo Alto, CA: Stanford University Press.

Gottfredson, M., \& Hirschi, T. (2003). A general theory of crime. In F. Cullen \& R. Agnew (Eds.), Criminological theory: Past to present (pp. 240-252). Los Angeles: Roxbury.

Goudriaan, H., \& Nieuwbeerta, P. (2007). Contextual determinants of juveniles' willingness to report crimes: A vignette experiment. Journal of Experimental Criminology, 3, 89-111.

Gover, A. R. (2004). Risky lifestyles and dating violence: A theoretical test of violent victimization. Journal of Criminal Justice, 32, 171-180.

Hall, R. F., Graham, R. D., \& Hoover, G. A. (2004). Sexual harassment in higher education: A victim's remedies and a private university liability. Education and the Law, 16, 33-45.

Hamilton, M. B. (2003). Online survey response rates and times: Background and guidance for industry. Retrieved November 27, 2007, from http://www.supersurvey.com.

Hine, C. (2005). Virtual methods: Issues in social research on the Internet. New York: Berg.

Ivy, D. K., \& Hamlet, S. (1996). College students and sexual dynamics: Two studies of peer sexual harassment. Communication Education, 45, 149-166.

Kalof, L. (2000). Vulnerability to sexual coercion among college women: A longitudinal study. Gender Issues, 18, 47-58.

Kalof, L., Eby, K. K., Matheson, J. L., \& Kroska, R. J. (2001). The influence of race and gender on student self-reports of sexual harassment by college professors. Gender and Society, 15, 282-302.

Kelley, M. L., \& Parsons, B. (2000). Sexual harassment in the 1990s: A university-wide survey of female faculty, administrators, staff, and students. Journal of Higher Education, 71, 548-568.

Koss, M. P., Gidycz, C. A., \& Wisniewski, N. (1987). The scope of rape: Incidence and prevalence of sexual aggression and victimization in a national sample of higher education students. Journal of Consulting and Clinical Psychology, 55, 162-170.

Koss, M. P. (2000). Shame, blame, and community: Justice responses to violence against women. American Psychologist, 55, 1332-1343.

Larimer, M. E., Lydum, A. R., Anderson, B. K., \& Turner, A. P. (1999). Male and female recipients of unwanted sexual contact in a college student sample: Prevalence rates, alcohol use, and depression symptoms. Sex Roles, 40, 295-308.

LaRocca, M. A., \& Kromrey, J. (1999). The perception of sexual harassment in higher education: Impact of gender and attractiveness-Statistical data included. Sex Roles: A Journal of Research. Retrieved April 14, 2005, from http://www.findarticles.com/p/articles/mi_m2294/ is_11_40/ai_ai57533232.

Leppel, K. (2006). College binge drinking: Deviant versus mainstream behavior. American Journal of Drug and Alcohol Abuse, 32, 519-525.

Littleton, H. L., Axsom, D., Breitkopf, C. R., \& Berenson, A. (2006). Rape acknowledgment and postassault experiences: How acknowledgment status relates to disclosure, coping, worldview, and reactions received from others. Violence and Victims, 21, 761-78.

Littleton, H. L., Axsom, D., \& Yoder, M. (2006). Experimental test of the role of scripts in rape attributions. Sex Roles, 54, 557-563.

Magley, V. J., \& Shupe, E. I. (2005). Self-labeling sexual harassment. Sex Roles, 53, 173-189.

Menard, K., Hall, G., Phung, A., Ghebrial, M., \& Martin, L. (2003). Gender differences in sexual harassment and coercion in college students: Developmental, individual, and situational determinants. Journal of Interpersonal Violence, 18, 1222-1239.

Moffitt, T. E. (2003). Pathways in the life course to crime. In F. T. Cullen \& R. Agnew (Eds.), Criminological theory: Past to present (pp. 450-469). Los Angeles: Roxbury. 
Mustaine, E. E., \& Tewksbury, R. (1999). A routine activity theory explanation for women's stalking victimizations. Violence Against Women, 5, 43-62.

Paludi, M. (1997). Sexual harassment in schools. In W. O'Donohue (Ed.), Sexual harassment: Theory, research, and treatment (pp. 225-249). Boston: Allyn \& Bacon.

Parks, K. A., \& Fals-Stewart, W. (2004). The temporal relationship between college women's alcohol consumption and victimization experiences. Alcohol: Clinical and Experimental Research, 28, 625-629.

Piquero, A. R., Brame, R., Mazerolle, P., \& Hapaanen, R. (2002). Crime in emerging adulthood. Criminology, 40, 137-170.

Pratt, T. P., \& Cullen, F. T. (2000). The empirical status of Gottfredson and Hirschi's general theory of crime: A meta-analysis. Criminology, 38, 931-964.

Reiss, A. J. (1971). The police and the public. New Haven, CT: Yale University Press.

Rickert, V. I., Wiemann, C. M., \& Vaughan, R. D. (2005). Disclosure of date/acquaintance rape: Who reports and when. Journal of Pediatric and Adolescent Gynecology, 18, 17-24.

Rothman, E., \& Silverman, J. (2007). The effect of a college sexual assault prevention program on first-year students' victimization rates. Journal of American College Health, 55, 283-290.

Rubin, P. N. (1995). Civil rights and criminal justice: Primer on sexual harassment. Research in action (NCJ Publication No. 156663). Washington, DC: Department of Justice.

Russell, B. L., \& Oswald, D. L. (2001). Strategies and dispositional correlates of sexual coercion perpetrated by women: An exploratory investigation. Sex Roles, 45, 103-115.

Schneider, B. E. (1987). Graduate women, sexual harassment, and university policy. Journal of Higher Education, 58, 46-65.

Schreck, C. J. (1999). Criminal victimization and low self-control: An extension and test of a general theory of crime. Justice Quarterly, 16, 633-65.

Sheehan, K. B. (2001). E-mail survey response rates: A review. Journal of ComputerMediated Communication, 6. Retrieved from http://jcmc.indiana.edu/v016/issue2/sheehan.html.

Shelton, J. N., \& Chavous, T. M. (1999). Black and white college women's perceptions of sexual harassment. Sex Roles, 40, 593-615.

Spitzberg, B. H. (1999). An analysis of empirical estimates of sexual aggression victimization and perpetration. Violence and Victims, 14, 241-260.

Stewart, E. A, Elifson, K. W., \& Sterk, C. E. (2004). Integrating the general theory of crime into an explanation of violent victimization among female offenders. Justice Quarterly, $21,159-180$.

Streiner, D. L. (2003). Starting at the beginning: An introduction to coefficient alpha and internal consistency. Journal of Personality Assessment, 80, 99-103.

Testa, M., \& Parks, K. A. (1996). The role of women's alcohol consumption in sexual victimization. Aggression and Violent Behavior, 1, 217-234.

Tjaden, P., \& Thoennes, N. (2000). Extent, nature, and consequences of intimate partner violence: Findings from the National Violence Against Women Survey (NCJ Publication No. 181867). Washington, DC: Department of Justice.

Turner, M. G., \& Piquero, A. R. (2002). The stability of self-control. Journal of Criminal Justice, 30, 457-471.

Unnever J. D., \& Cornell, D. G. (2003). Bullying, self-control, and ADHD. Journal of Interpersonal Violence, 18, 129-147.

U.S. Department of Education, National Center for Education Statistics. (2007). The Condition of Education 2007 (NCES 2007-064). Washington, DC: U.S. Government Printing Office. 
U.S. Department of Health and Human Services. (2006). Results from the 2006 National Survey on Drug Use and Health: National findings. Rockville, MD: Substance Abuse and Mental Health Services Administration, Office of Applied Studies.

Visher, C. A. (1983), Gender, police arrest decisions and notions of chivalry. Criminology, 21, 5-28.

Weitzman, E. R., \& Nelson, T. F. (2004). College student binge drinking and the "prevention paradox": Implications for prevention and harm reduction. Journal of Drug Education, 34, 247-266.

Williams, E. A., Lam, J. A., \& Shively, M. (1992). The impact of a university policy on the sexual harassment of female students. Journal of Higher Education, 63, 50-64.

Wilson, A. E., Calhoun, K. S., \& McNair, L. D. (2002). Alcohol consumption and expectancies among sexually coercive college men. Journal of Interpersonal Violence, $17,1145-1159$.

Tammatha A. Clodfelter is a doctoral student in the Public Policy Program at the University of North Carolina at Charlotte. She serves as a research assistant to the Department of Criminal Justice at the University of North Carolina at Charlotte, where she received her master's degree in criminal justice. Her research interests include sexual victimization, intimate partner violence, the links between substance abuse and victimization, and justice policy.

Michael G. Turner is an associate professor in the Department of Criminal Justice at the University of North Carolina at Charlotte. His research interests include testing criminological theories and victimization. He has recently published in Journal of Research in Crime and Delinquency, Justice Quarterly, and Criminal Justice and Behavior.

Jennifer L. Hartman is an assistant professor in the Department of Criminal Justice at the University of North Carolina at Charlotte with an adjunct professor appointment in the Women's and Gender Studies Department. Dr. Hartman earned her PhD from University of Cincinnati. She is the author of more than 20 journal articles, academic book chapters, and technical reports focused on gender issues, domestic violence, and best court and community correctional practices. Her recent publications have focused on the gendered effects of methamphetamine users in a community setting. Her recently published work has appeared in Criminal Justice and Behavior and Crime and Delinquency.

Joseph B. Kuhns is an assistant professor in the Department of Criminal Justice of the University of North Carolina at Charlotte. Prior to joining the faculty of the university, he served for 8 years as a senior policy analyst and supervisor and a social science analyst for the U.S. Department of Justice, Office of Community Oriented Policing Services. Dr. Kuhns has worked on dozens of research and evaluation projects that focused on spouse abuse and homicide, reducing harms associated with prostitution, community policing in small cities and towns, managing the growth of police agencies, and drug and violent crime relationships. He is currently working with a number of scholars and with the Trinidad and Tobago Police Services to help reduce violent crime and improve law enforcement services in that developing country. $\mathrm{He}$ is also working with colleagues to reduce prostitution solicitation in the Charlotte area. Finally, Dr. Kuhns continues to explore the relationship between drug use and violent behavior by analyzing toxicology data within and outside of the United States. 